\title{
Targeting IKK $\alpha$ kinase to prevent tumor progression and therapy resistance
}

\author{
Carlota Colomer, Irene Pecharroman, Anna Bigas, Lluís Espinosa \\ Cancer Research Program, Institut Mar d'Investigacions Mèdiques, CIBERONC, Hospital del Mar, Barcelona 08003, Spain.
}

Correspondence to: Lluís Espinosa, Institut Hospital delMar d'Investigacions Mèdiques, IMIM, Dr. Aiguader 88, Barcelona 08003, Spain. E-mail: lespinosa@imim.es

\begin{abstract}
How to cite this article: Colomer C, Pecharroman I, Bigas A, Espinosa L. Targeting IKK $\alpha$ kinase to prevent tumor progression and therapy resistance. Cancer Drug Resist 2020;3:482-90. http://dx.doi.org/10.20517/cdr.2019.104
\end{abstract}

Received: 4 Nov 2019 First Decision: 20 Dec 2019 Revised: 14 Feb 2020 Accepted: 4 Mar 2020 Available online: 21 Mar 2020

Science Editor: Lee M. Graves Copy Editor: Jing-Wen Zhang Production Editor: Jing Yu

\begin{abstract}
Cancer therapy has improved considerably in the last years; however, therapeutic resistance is still a major problem that impedes full response to the treatment and the main cause of patient relapse and death. Numerous kinases have been reported to be overactivated in cancer and induce resistance to current therapies. Targeting kinases has proven to be useful for overcoming chemotherapy resistance and thus improving patient outcomes. Inhibitor of kappaB kinase alpha (IKK $\alpha$ ) is a serine/threonine kinase that was first described as part of the IKK complex in the nuclear factor- $\mathrm{KB}(\mathrm{NF}-\mathrm{\kappa} \mathrm{B})$ pathway, which regulates several physiological and physiopathological processes such as immunity, inflammation, and cancer. However, the IKK $\alpha$ subunit has been shown to be dispensable for NF$\kappa B$ activation and responsible of multiple pro-tumorigenic functions. Furthermore, we identified a nuclear active

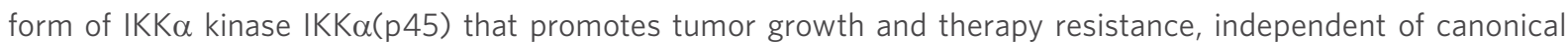
$\mathrm{NF}-\mathrm{\kappa B}$. Improved understanding of resistance mechanisms will facilitate drug discovery and provide new effective therapies. Here, we review the recent publications on the implications of IKK $\alpha$ in cancer initiation, development, and resistance.
\end{abstract}

Keywords: IKK $\alpha$, cancer, therapeutic targets, chemoresistance

\section{INTRODUCTION}

Cancer is the second leading cause of death worldwide ${ }^{[1]}$. Specific genetic background, exposure to various environmental stresses, and unhealthy diets are the main factors that lead to the accumulation of molecular changes or mutations that will contribute to the initiation and progression of carcinogenesis.

cc) (i) The Author(s) 2020. Open Access This article is licensed under a Creative Commons Attribution 4.0 International License (https://creativecommons.org/licenses/by/4.0/), which permits unrestricted use sharing, adaptation, distribution and reproduction in any medium or format, for any purpose, even commercially, as long as you give appropriate credit to the original author(s) and the source, provide a link to the Creative Commons license, and indicate if changes were made.

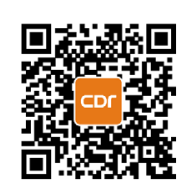


The mainstream therapeutic approaches to treat cancer patients are surgery, irradiation, and chemotherapy. However, its success is limited due to lack of selectivity for tumor cells over rapidly dividing non-malignant cells (e.g., bone marrow and gastrointestinal tract cells) resulting in several toxic side effects. Tumor response to these highly toxic non-specific chemotherapeutic agents is usually partial, transitory, and unpredictable and very frequently patients develop therapy resistance, which is a leading reason for tumor relapse and poor survival in cancer patients.

In recent years, targeted therapy and immunotherapy has been introduced as a breakthrough for cancer therapy. In contrast to chemotherapy, these therapies are directed against cancer-specific molecules and signaling pathways, which give high specificity toward tumor cells and provides a broader therapeutic window $^{[2]}$. They are also often useful in combination with chemotherapy or radiation to produce additive or synergistic anticancer activity because their toxicity profiles often do not overlap with traditional cytotoxic chemotherapy. However, immunotherapy presents new challenges related with other adverse events, such as cytokine release syndrome and neurological toxicity in the case of chimeric antigen receptor- $\mathrm{T}$ cells against CD19 for treatment of B-acute lymphoblastic leukemia.

Deregulation of kinase activity has emerged as a major mechanism by which cancer cells evade normal physiological constraints on growth and survival, making them one of the most intensively pursued classes of drug targets for cancer therapy. To date, 52 kinase inhibitors have received United States Food and Drug Administration approval for cancer treatment ${ }^{[3]}$, and there are considerable efforts to develop selective small molecule inhibitors for a number of other kinases that are implicated in cancer.

One kinase that is increasingly envisioned as a target for the development of novel anti-cancer therapies is IKK $\alpha$. Traditionally, IKK $\alpha$ has been characterized for its critical role in the regulation of the immune response through the nuclear factor- $\mathrm{KB}(\mathrm{NF}-\kappa \mathrm{B})$ signaling pathway. More recently, different studies have shown that IKK $\alpha$ is implicated in the pathogenesis and resistance to treatment ${ }^{[4,5]}$ of many human diseases, including cancer $^{[6]}$. Dysregulation of IKK $\alpha$ promotes tumor survival, proliferation, migration, metastasis, and angiogenesis, which are common hallmarks of many human tumors.

\section{PHYSIOLOGIC IKK $\alpha$ FUNCTIONS}

As mentioned above, IKK $\alpha$ is an essential regulator of the NF- $\mathrm{KB}$ pathway ${ }^{[7]}$ downstream of multiple proinflammatory factors, such as tumor necrosis factor alpha $(\mathrm{TNF} \alpha)$, interleukin-1, and toll-like receptor agonists. In brief, binding of these factors to specific receptors induces the recruitment of TGF $\beta$-activated kinase 1 (TAK1) into the proximity of the IKK complex [formed by the catalytic subunits IKK $\alpha$ and IKK $\beta$ and the regulatory subunit NF- $\kappa \mathrm{B}$ essential modulator (NEMO) $]^{[8]}$, thereby phosphorylating and activating both kinases in the cytoplasm. A major consequence of IKK activation is the initiation of NF- $\kappa \mathrm{B}$-mediated transcriptional activation of a large subset of genes (more than 150 target genes) ${ }^{[9,10]}$. Although these two kinases have a high degree of structural similarity and are both present in the IKK complex, their downstream substrates and physiologic functions can be quite different. In fact, both IKK $\alpha$ and IKK $\beta$ have recently been shown to function independently of each other and to have non-overlapping functions ${ }^{[1]}$.

Several natural compounds and synthetic drugs have shown to inhibit IKK activity and prevent cancer or cell growth in animal models ${ }^{[12-14]}$. However, these compounds are extremely toxic due to its effect on the classical NF- $\mathrm{B}$ pathways, which are indispensable for multiple cellular functions, inflammation, and immunity ${ }^{[15]}$. Importantly, IKK $\alpha$ activity is not required for canonical NF- $\kappa \mathrm{B}$ signal activation and regulation of the immune system (that mainly depends on IKK $\beta$ ), but there is increasing evidence of its involvement in the phosphorylation of NF- $\mathrm{BB}$-unrelated substrates that participate in diverse biological processes, including tumorigenesis ${ }^{[16]}$. A few years ago, our group identified a truncated form of IKK $\alpha$, 
generated by the proteolytic cleavage of full length IKK $\alpha$ in the endosomal compartment, with a predicted molecular weight of $45 \mathrm{kD}$, that we called IKK $\alpha(\mathrm{p} 45)$ and is present in different cell types but specifically activated in the nucleus of cancer cells ${ }^{[17]}$. The $\operatorname{IKK} \alpha(\mathrm{p} 45)$ form includes the kinase domain but lacks some regulatory domains at the c-terminal region of the protein. We proposed that $I K K \alpha(\mathrm{p} 45)$ might be responsible for the multiple functions that have been ascribed to nuclear IKK $\alpha$ including histone 3 phosphorylation, regulation of specific gene transcription, cancer progression, and metastasis ${ }^{[1-23]}$. Here, we discuss the latest advances on IKK $\alpha$ and the $\operatorname{IKK} \alpha(\mathrm{p} 45)$ form in cancer initiation, progression, and therapy resistance, as well as the strategies to inhibit its activity.

\section{IKK $\alpha$ IN CANCER INITIATION}

One of the first pieces of evidence of an NF- $\mathrm{KB}$-independent role for IKK $\alpha$ in cancer was the observation that IKK $\alpha$ deletion in keratinocytes induces skin squamous cell carcinoma in mice. In particular, it was shown that IKK $\alpha$ binds the chromatin at the $14-3-3 \sigma$ locus to support its expression, which negatively regulates the cell cycle phosphatase $\mathrm{CDC} 25$. In the absence of $14-3-3 \sigma$, cells aberrantly proliferate, which results in the loss of skin homeostasis and increased cell transformation ${ }^{[18]}$. Other works also supported and further explored this tumor suppressor function of IKK $\alpha$ in the skin, and suggested an association of the kinase with the transforming growth factor beta (TGF $\beta$ ) pathway ${ }^{[2,25]}$. It was also shown that mice carrying an IKK $\alpha$ variant that specifically localizes to the nucleus of the keratinocytes develop more aggressive tumors in response to chemical carcinogens ${ }^{[26]}$.

In contrast, IKK $\alpha$ activity promotes human lung adenocarcinoma in Kirsten Rat Sarcoma (KRAS)-mutant cells and in response to chemical carcinogens. In addition, respiratory epithelial IKK $\alpha$-deficient mice were strikingly protected from disease. Mechanistically, IKK $\alpha$ potentiates mutant KRAS-induced tumorigenesis in a cell-autonomous fashion, by providing mutant cells with a survival advantage in vitro and in vivo ${ }^{[27]}$. In a similar setting, it has been shown that nuclear IKK $\alpha$ phosphorylates CREB-binding protein after TNF $\alpha$ stimulation, switching its binding preference from p53 to NF- $\kappa$ B. Hence, IKK $\alpha$ activity not only facilitates $\mathrm{NF}-\kappa \mathrm{B}$-dependent gene expression, but also suppresses p53-induced transcription, leading to increased cell proliferation and tumor growth ${ }^{[28]}[$ Figure 1].

In Basal Cell Carcinoma, nuclear IKK $\alpha$ is over-expressed and it directly binds to the LGR5 promoter, upregulating its expression. By a similar mechanism, murine IKK $\alpha$ contributes to self-renewal of breast cancer progenitors ${ }^{[29]}$. This suggests that IKK $\alpha$ activity can contribute to oncogenic transformation not only through inflammatory-related signals but also through the regulation of stemness-related genes ${ }^{[30]}$. In line with this, our group demonstrated that intestinal-specific deletion of IKK $\alpha$ does not affect intestinal homeostasis but greatly decreases tumor initiation in the $A p c^{\mathrm{Min} /+}$ background, associated with reduced stem cell-related gene transcription and proliferation ${ }^{[31]}$. In a different study, our group identified IKK $\alpha$ as an essential regulator of nuclear Inhibitor of kappaB $\alpha$, which acts as a switch for multiple developmental- and stemness-related genes such as homeobox (HOX) and iroquois (IRX). IKK $\alpha$ activity on PS-IKB $\alpha$ induces its chromatin release and HOX activation, which is linked to oncogenic keratinocyte transformation ${ }^{[32]}$.

\section{IKK $\alpha$ IN CANCER PROGRESSION}

IKKa's role in cancer is not only limited to its function in cancer initiation but also in cancer progression and metastasis. For instance, in colorectal cancer (CRC) cells, IKK $\alpha$ is aberrantly activated in the nucleus of tumor cells and bound to the promoter of different Notch-dependent genes, including hes 1 and herp2 ${ }^{[19]}$. Nuclear IKK $\alpha$ phosphorylates the nuclear co-repressor silencing-mediator for retinoid/thyroid hormone receptors (SMRT), leading to its chromatin release ${ }^{[22]}$ and Notch-dependent gene expression ${ }^{[33]}$. General IKK inhibition restores SMRT chromatin binding, thus inhibiting Notch-dependent gene expression and preventing tumor growth in a xenograft model of nude mice. In a similar fashion, IKK $\alpha$ phosphorylates 


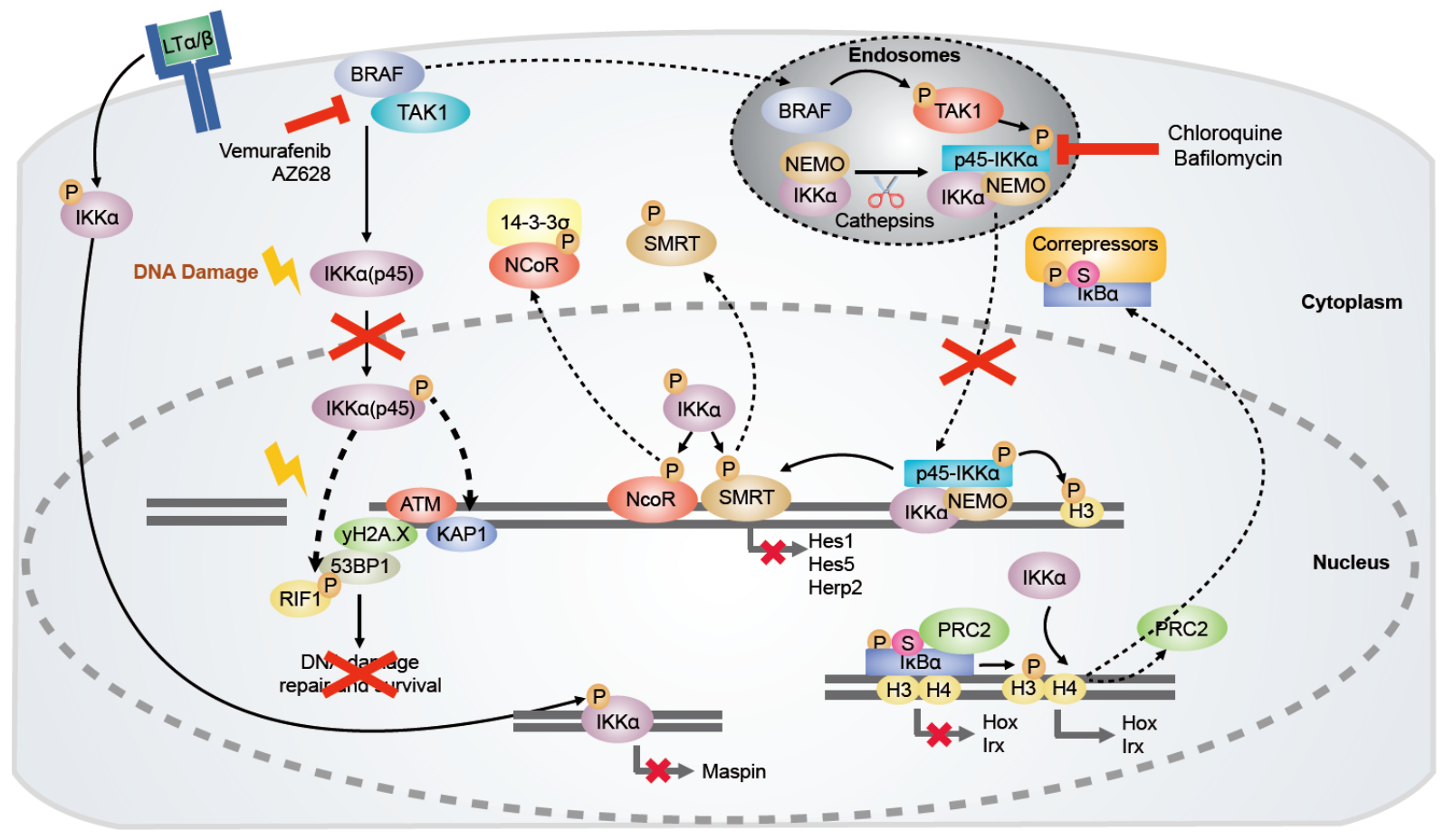

Figure 1. Tumorigenic functions of IKK $\alpha$ and IKK $\alpha(p 45)$. In CRC, IKK $\alpha$ phosphorylates the nuclear co-repressors N-CoR and SMRT, inducing their dissociation from chromatin. IKK $\alpha(\mathrm{p} 45)$ is activated by BRAF and TAK1 in the endosomal compartment, and upon activation phosphorylates histone H3 and SMRT. Inhibitors of the endosomal acidification such as chloroquine or Bafilomycin A1 would prevent IKK $\alpha(\mathrm{p} 45)$ phosphorylation and impair gene transcription necessary for cancer cell survival. Moreover, nuclear active IKK $\alpha$ contributes to chromatin release of phospho-SUMO-IKB $\alpha$ facilitating its cytoplasmic export. IKK $\alpha$ regulates gene transcription of metastasis repressor Maspin in prostate cancer cells. Under damaging conditions, IKK $\alpha(\mathrm{p} 45)$ is phosphorylated via BRAF/TAK1/p38MAPK, inducing its nuclear translocation. In the nucleus, IKK $\alpha(\mathrm{p} 45)$ induces phosphorylation of ATM and 53BP1, which would favor the recruitment of RIF1 to $53 \mathrm{BP}^{[4]}$. Altogether, the activation of these factors would induce DNA repair and survival of cancer cells. Blocking BRAF activity would block IKK $\alpha(\mathrm{p} 45)$ activation and cancer cell survival. Arrows indicate activation/regulation/phosphorylation, dashed arrows indicate migration, and the red cross indicates inactivation. CRC: colorectal cancer; IKK $\alpha$ : inhibitor of kappaB kinase alpha; BRAF: serine/threonine-specific protein kinase of the RAF family; TAK1: TGF $\beta$-Activated kinase 1; SMRT: silencing-mediator for retinoid/ thyroid hormone receptors; MAPK: mitogen-activated protein kinase; ATM: ataxia telangiectasia mutated gene; NEMO: NF- $\mathrm{KB}$ essential modulator; PRC2: polycomb repressive complex 2; KAP1: KRAB-associated protein-1; RIF1: replication timing regulatory factor 1

$\mathrm{N}-\mathrm{CoR}$, which is closely related to SMRT, in CRC cells, creating a functional 14-3-3 binding domain and facilitating its nuclear export ${ }^{[20]}$. Interestingly, the nuclear active IKK $\alpha$ isoform $\operatorname{IKK} \alpha(\mathrm{p} 45)$ is required to prevent apoptosis in CRC cells, thus increasing tumor growth. Mechanistically, we demonstrated that BRAF is required for the association of active TAK1 with a complex that contains $\operatorname{IKK} \alpha(\mathrm{p} 45)$, full length IKK $\alpha$, and NEMO, leading to its activation. Importantly, active nuclear $\mathrm{IKK} \alpha(\mathrm{p} 45)$ mediates phosphorylation of SMRT and Histone $\mathrm{H} 3$ and is required for BRAF-mediated transformation but has no impact on NF- $\mathrm{kB}$ signaling ${ }^{[34]}$.

In prostate cancer cells, nuclear IKK $\alpha$ negatively regulates the expression of Maspin, a well-characterized metastasis suppressor, presumably by facilitating the recruitment of DNA methyltransferase activity to its promoter, independent of $\mathrm{NF}-\mathrm{KB}^{[35,36]}$. Similarly, nuclear active IKK $\alpha$ promotes skin tumorigenesis by regulating $c-M y c$, Maspin, and Integrin- $\alpha 6$ transcription. Tumors carrying nuclear IKK $\alpha$ mimic the characteristics of human skin tumors with high risk to metastasize ${ }^{[26]}$. These results are in agreement with previous findings of our group indicating that high levels of nuclear active IKK $\alpha$ are predictive of higher metastatic capacity in human squamous cell carcinoma and worse patient outcome ${ }^{[37]}$. In nonsmall cell lung cancer, IKK $\alpha$ promotes increased cell malignancy through activation of different signaling pathways, depending on its subcellular localization. In particular, cytoplasmic IKK $\alpha$ increases epidermal growth factor receptor (EGFR) and NF- $\mathrm{B}$ activities, whereas nuclear IKK $\alpha$ leads to an increase in c-Myc, $\mathrm{P}-\mathrm{Smad} 2 / 3$, and Snail levels ${ }^{[38]}$. 
IKK $\alpha$ is also responsible for the tumor-promoting effect of progesterone in breast cancer downstream of receptor activator of NF- $\mathrm{KB}$ ligand (RANKL) induction ${ }^{[39,40]}$ and for the metastatic spread of breast cancer cells, which depends on RANKL produced by tumor-infiltrating regulatory $\mathrm{T}$ cells ${ }^{[4]}$. IKK $\alpha$ also phosphorylates Estrogen Receptor $\alpha$, its coactivator AIB1/SRC3, and induces downstream targets such as cyclin D1 and c-myc, promoting breast cancer cell proliferation as well ${ }^{[42,43]}$. In a clinical study, Bennett et $a l .{ }^{[4]}$ observed that IKK $\alpha$ expression in breast cancer cells is associated with patient outcome independently of their cellular localization. In triple negative breast cancer (TNBC) cells, Notch ligand Jagged 1 triggers IKK $\alpha$-dependent Notch signaling, which is a key pathway regulating TNBC Cancer Stem Cell survival. These data suggest that combination treatments targeting the intersection of the Notch, AKT, and NF- $\kappa B$ pathways have potential therapeutic applications against CSCs in $\mathrm{TNBC}^{[45]}$.

\section{IKK $\alpha$ IN THERAPY RESISTANCE}

Apart from its role in tumor initiation and progression, recent results from our group demonstrated that IKK $\alpha$, and, in particular, IKK $\alpha(\mathrm{p} 45)$, is activated not only in cancer cells carrying mutant BRAF, but also in cells possessing wild-type KRAS and BRAF in response to stimuli that induce DNA damage, such as chemotherapy or irradiation ${ }^{[4]}$. Activation of $\operatorname{IKK} \alpha(\mathrm{p} 45)$ by these damaging agents is BRAF/TAK1/ p38-dependent. The most important finding was that damage-induce $I K K \alpha(p 45)$ regulates activation of the DNA damage response (DDR) pathway by directly phosphorylating the Ataxia Telangiectasia Mutated (ATM) kinase leading to efficient DNA repair. Consequently, IKK $\alpha$ or BRAF inhibition or downregulation reduces phosphorylation/activation of key DDR elements such as ATM and 53BP1 after exposure of cells to chemo/radiotherapy, leading to sustained DNA damage. We formally demonstrated that IKK $\alpha$ or BRAF inhibition (by precluding DNA damage repair) synergistically enhance the therapeutic potential of the standard of care therapy in CRC (5-FU plus irinotecan), leading to the eradication of chemotherapy-resistant metastatic human tumors in vivo. These findings are of paramount significance for the field of cancer therapy since they provide a rationale for using BRAF and IKK $\alpha$ inhibitors as a novel combination strategy for cancer treatment or even for treating patients who have become resistant to single chemotherapy (or radiotherapy) regimes. We are currently evaluating the potential use of EGFR inhibitors, which act upstream of BRAF and therefore IKK $\alpha(\mathrm{p} 45)$ activation, in combination with DNA damaging agents for the treatment of KRAS and BRAF wild type tumors.

\section{STRATEGIES TO INHIBIT IKK $\alpha$}

Given the growing evidence that IKK $\alpha$ plays an important role in a number of cancers through direct regulation of multiple elements [Figure 1], the development of selective IKK $\alpha$ inhibitors or molecules that target IKK $\alpha$ (and its downstream pathways) are an attractive approach for the pharmaceutical industry that focuses on cancer therapy. To date, reported inhibitors have either been pan-IKK inhibitors or IKKb selective compounds, which are associated with several side effects that have been extensively reviewed ${ }^{[12-14]}$. Among them, we can find a variety of natural products ${ }^{[46-48]}$, biomolecular and peptide inhibitors ${ }^{[49]}$, and synthetic small-molecule inhibitors ${ }^{[14,50]}$. However, recent efforts have been made to inhibit other elements beyond IKKb. This includes the development of apigenin, which inhibits IKK $\alpha$ and NF- $\mathrm{KB} / \mathrm{p} 65$ activities and demonstrates to have anti-proliferative and anti-invasive effects in cell-based assays and anticancer efficacy in experimental tumor models ${ }^{[51]}$. Leopizzi et al. ${ }^{[52]}$ developed a glucosamine derivative, NCPA [2-( $N$-Carbobenzyloxy)l-phenylalanylamido-2-deoxy- $\beta$-d-glucose], which inhibits IKK $\alpha$ nuclear translocation, thus increasing Maspin expression and inhibiting cell migration. Another group has reported the first series of selective IKK $\alpha$ inhibitors, which effectively inhibit IKK $\alpha$-driven p100 phosphorylation in $\mathrm{U} 2 \mathrm{OS}$ cells without affecting IKKb-mediated activation of $\mathrm{NF}-\kappa \mathrm{B}^{[53]}$.

Surprisingly, even though IKK inhibitors have been used for years as reliable tools for research and have proven their positive effects in a variety of experimental cancer models ${ }^{[34,50,54,5]}$, they have not yet been able 
to move beyond animal studies. As mentioned, this is in part due to the high level of homology between $\mathrm{IKK} \alpha$ and IKKb that makes it difficult to discriminate between cancer-related IKK function (several ascribed to $I K K \alpha$ ) and NF- $\kappa B$ signaling (IKKb dependent), which is essential for a number of biological processes including inflammation and immunity. Interestingly, Prescott et al. ${ }^{[15]}$ and Lee et al ${ }^{[50]}$ described in detail all the commercially available IKKb and IKK $\alpha$ inhibitors, respectively. The recent discovery that BRAF acts upstream of IKK $\alpha(\mathrm{p} 45)$ phosphorylation and activation in CRC cells, as well as other cancer types, which does not impact on NF- $\kappa \mathrm{B}$ activation, might have important implications in this scenario. Consistently, we demonstrated that IKK $\alpha(\mathrm{p} 45)$ activation can be abolished using different inhibitors of BRAF without affecting classical NF- $\kappa B$ signaling and thus without imposing toxic effects to normal cells. Several of these BRAF inhibitors are currently used in clinical practice for specific anti-cancer therapies including CRC treatment. Another therapeutic option to prevent IKK $\alpha(\mathrm{p} 45)$ phosphorylation is the use of inhibitors of TAK1, which is the kinase that directly phosphorylates IKK $\alpha(\mathrm{p} 45)$ in the IKK complex. However, TAK1 participates in the activation of other signaling cascades ${ }^{[56]}$, such as classical NF- $\kappa \mathrm{B}$ pathway ${ }^{[57]}$ or TGF $\beta^{[58]}$, and in fact there are no TAK1 inhibitors currently approved for treating patients. Because IKK $\alpha(\mathrm{p} 45)$ activation by TAK1 and BRAF takes place in the endosomal compartment, a third possibility for inhibiting IKK $\alpha$ in CRC cells would be the use of inhibitors of the endosomal vacuolar adenosine triphosphatase (V-ATPase), such as chloroquine or bafilomycin A1. Indeed, Margalef et al. ${ }^{[34]}$ demonstrated that treatment of CRC cells with chloroquine or bafilomycin A1 induces apoptosis of cancer cells in vitro, and reduces growth and metastasis of a BRAF-mutant xenograft model derived from a patient with acquired resistance to standard chemotherapy.

In human lung adenocarcinoma, IKK $\alpha$ has been shown to be highly expressed and it has been demonstrated that a heat shock protein 90 (HSP90) inhibitor blocks IKK function and has superior efficacy against KRAS-mutant lung adenocarcinoma compared with a specific IKKb inhibitor ${ }^{[27]}$.

Finally, it is important to indicate here that, independently of the tumor type, identifying the mechanisms leading to IKK activation, either cell autonomous (i.e., mutations in specific upstream regulators of the pathway) or induced by adjacent cells from tumor microenvironment, would also allow the identification of new strategies to prevent IKK activation with relevance for cancer therapy.

\section{CONCLUSIONS AND PERSPECTIVES}

From the current data, the most realistic possibility for using IKK inhibitors to treat therapy-resistant cancers would involve the combination of compound inhibiting basal or therapy-induced IKK $\alpha$ activity with the more traditional chemo- and radiotherapeutic agents. For instance, our group recently demonstrated that IKK $\alpha$ or BRAF inhibition [leading to abrogation of IKK $\alpha(\mathrm{p} 45)$ activity] synergizes with chemotherapeutic (DNA-damaging) agents to induce tumor eradication in a xenograft mouse model derived for a chemotherapy-resistant human CRC that had already metastasized to the liver of the patient ${ }^{[4]}$. These findings expand the potential use of combination protocols including IKK $\alpha$ and/or BRAF inhibitors, which are currently used as single agents exclusively in patients carrying BRAF mutated tumors. Because all these experimental approaches have been developed in cells, organoids, xenografts, and mouse models, the possibility of using this kinase inhibitors with one of the multiple immunotherapy strategies that are currently in use or under investigation remains unexplored. These would require the use of humanized mouse models (immune-reconstituted) or novel in vitro systems that support the maintenance of mixed populations of cancer and immune cells.

\section{DECLARATIONS}

\section{Authors' contributions}

Wrote the manuscript: Colomer C, Pecharroman I

Designed the structure and content of the manuscript and supervised and corrected the final version: Bigas A, Espinosa L 


\section{Availability of data and materials}

Not applicable.

\section{Financial support and sponsorship}

None.

\section{Conflicts of interest}

All authors declared that there are no conflicts of interest.

\section{Ethical approval and consent to participate}

Not applicable.

\section{Consent for publication}

Not applicable.

\section{Copyright}

(c) The Author(s) 2020.

\section{REFERENCES}

1. Global Burden of Disease Collaborative Network. Global Burden of Disease Study 2016 (GBD 2016) Results [Institute for Health Metrics and Evaluation (IHME), 2017]. Available from https:/www.who.int/news-room/fact-sheets/detail/cancer [Last accessed on 20 Mar 2020]

2. Kannaiyan R, Mahadevan D. A comprehensive review of protein kinase inhibitors for cancer therapy. Expert Rev Anticancer Ther 2018;18:1249-70.

3. Roskoski R Jr. Properties of FDA-approved small molecule protein kinase inhibitors: a 2020 update. Pharmacol Res 2020;152:104609.

4. Colomer C, Margalef P, Villanueva A, Vert A, Pecharroman I, et al. IKK $\alpha$ kinase regulates the DNA damage response and drives chemoresistance in cancer. Mol Cell 2019;75:669-82.e5.

5. Roseweir AK, Bennett L, Dickson A, Cheng K, Quintayo MA, et al. Predictive biomarkers for endocrine therapy: retrospective study in tamoxifen and exemestane adjuvant multinational (TEAM) trial. J Natl Cancer Inst 2018;110:616-27.

6. Colomer C, Marruecos L, Vert A, Bigas A, Espinosa L. NF- $\kappa$ B members left home: NF- $\kappa$ B-independent roles in cancer. Biomedicines 2017;5:26.

7. Régnier CH, Song HY, Gao X, Goeddel DV, Cao Z, et al. Identification and characterization of an IкB kinase. Cell 1997;90:373-83.

8. Zandi E, Rothwarf DM, Delhase M, Hayakawa M, Karin M. The IkappaB kinase complex (IKK) contains two kinase subunits, IKKalpha and IKKbeta, necessary for IkappaB phosphorylation and NF-kappaB activation. Cell 1997;91:243-52.

9. Häcker H, Karin M. Regulation and function of IKK and IKK-related kinases. Sci STKE 2006;2006:re13.

10. Mercurio F. IKK-1 and IKK-2: cytokine-activated IאB kinases essential for NF-B activation. Science 1997;278:860-6.

11. Hinz M, Scheidereit C. The IкB kinase complex in NF- $\kappa$ B regulation and beyond. EMBO Rep 2014;15:46-61.

12. Gilmore TD, Herscovitch M. Inhibitors of NF- $\kappa B$ signaling: 785 and counting. Oncogene 2006;25:6887-99.

13. Gilmore TD, Garbati MR. Inhibition of NF- $\mathrm{B}$ signaling as a strategy in disease therapy. Curr Top Microbiol Immunol 2011;349:245-63.

14. Karin M, Yamamoto Y, Wang QM. The IKK NF-kappa B system: a treasure trove for drug development. Nat Rev Drug Discov 2004;3:17-26.

15. Prescott J, Cook S. Targeting IKK $\beta$ in cancer: challenges and opportunities for the therapeutic utilisation of IKK $\beta$ inhibitors. Cells 2018;7:115.

16. Chariot A. The NF-kappaB-independent functions of IKK subunits in immunity and cancer. Trends Cell Biol 2009;19:404-13.

17. Margalef P, Fernández-Majada V, Villanueva A, Garcia-Carbonell R, Iglesias M, et al. A truncated form of IKK $\alpha$ is responsible for specific nuclear IKK activity in colorectal cancer. Cell Rep 2012;2:840-54.

18. Zhu F, Xia X, Liu B, Shen J, Hu Y, et al. IKKalpha shields 14-3-3sigma, a G(2)/M cell cycle checkpoint gene, from hypermethylation, preventing its silencing. Mol Cell 2007;27:214-27.

19. Fernández-Majada V, Aguilera C, Villanueva A, Vilardell F, Robert-Moreno A, et al. Nuclear IKK activity leads to dysregulated notchdependent gene expression in colorectal cancer. Proc Natl Acad Sci U S A 2007;104:276-81.

20. Fernández-Majada V, Pujadas J, Vilardell F, Capella G, Mayo MW, et al. Aberrant cytoplasmic localization of N-CoR in colorectal tumors. Cell Cycle 2007;6:1748-52.

21. Anest V, Hanson JL, Cogswell PC, Steinbrecher KA, Strahl BD, et al. A nucleosomal function for I $\kappa$ B kinase- $\alpha$ in NF- $\kappa$ B-dependent gene expression. Nature 2003;423:659-63.

22. Hoberg JE, Yeung F, Mayo MW. SMRT derepression by the IkappaB kinase alpha: a prerequisite to NF-kappaB transcription and survival. Mol Cell 2004;16:245-55. 
23. Albanese C, Wu K, D'Amico M, Jarrett C, Joyce D, et al. IKKalpha regulates mitogenic signaling through transcriptional induction of cyclin D1 via Tcf. Mol Biol Cell 2003;14:585-99.

24. Marinari B, Moretti F, Botti E, Giustizieri ML, Descargues P, et al. The tumor suppressor activity of IKKalpha in stratified epithelia is exerted in part via the TGF-beta antiproliferative pathway. Proc Natl Acad Sci U S A 2008;105:17091-6.

25. Descargues P, Sil AK, Sano Y, Korchynskyi O, Han G, et al. IKKalpha is a critical coregulator of a Smad4-independent TGFbetaSmad2/3 signaling pathway that controls keratinocyte differentiation. Proc Natl Acad Sci U S A 2008;105:2487-92.

26. Alameda JP, Gaspar M, Ramírez Á, Navarro M, Page A, et al. Deciphering the role of nuclear and cytoplasmic IKK $\alpha$ in skin cancer. Oncotarget 2016;7:29531-47.

27. Vreka M, Lilis I, Papageorgopoulou M, Giotopoulou GA, Lianou M, et al. IkB kinase a is required for development and progression of KRAS-mutant lung adenocarcinoma. Cancer Res 2018;78:2939-51.

28. Ducut Sigala JL, Bottero V, Young DB, Shevchenko A, Mercurio F, et al. Activation of transcription factor NF-kB requires ELKS, an IkappaB kinase regulatory subunit. Science 2004;304:1963-7.

29. Cao Y, Luo JL, Karin M. IkappaB kinase alpha kinase activity is required for self-renewal of ErbB2/Her2-transformed mammary tumorinitiating cells. Proc Natl Acad Sci U S A 2007;104:15852-7.

30. Jia J, Shi Y, Yan B, Xiao D, Lai W, et al. LGR5 expression is controled by IKK $\alpha$ in basal cell carcinoma through activating STAT3 signaling pathway. Oncotarget. 2016;7:27280-94.

31. Colomer C, Margalef P, Gonzalez J, Vert A, Bigas A, et al. IKK $\alpha$ is required in the intestinal epithelial cells for tumour stemness. Br J Cancer 2018;118:839-46.

32. Mulero MC, Ferres-Marco D, Islam A, Margalef P, Pecoraro M, et al. Chromatin-bound IкB $\alpha$ regulates a subset of polycomb target genes in differentiation and cancer. Cancer Cell 2013;24:151-66.

33. Fernández-Majada V, Aguilera C, Villanueva A, Vilardell F, Robert-Moreno A, et al. Nuclear IKK activity leads to dysregulated Notchdependent gene expression in colorectal cancer. Proc Natl Acad Sci U S A 2007;104:276-81.

34. Margalef P, Colomer C, Villanueva A, Montagut C, Iglesias M, et al. BRAF-induced tumorigenesis is IKK $\alpha$-dependent but NF- $\kappa \mathrm{B}$ independent. Sci Signal 2015;8:ra38

35. Luo JL, Tan W, Ricono JM, Korchynskyi O, Zhang M, et al. Nuclear cytokine-activated IKK $\alpha$ controls prostate cancer metastasis by repressing Maspin. Nature 2007;446:690-4.

36. Ammirante M, Luo JL, Grivennikov S, Nedospasov S, Karin M. B-cell-derived lymphotoxin promotes castration-resistant prostate cancer. Nature 2010;464:302-5.

37. Toll A, Margalef P, Masferrer E, Ferrándiz-Pulido C, Gimeno J, et al. Active nuclear IKK correlates with metastatic risk in cutaneous squamous cell carcinoma. Arch Dermatol Res 2015;307:721-9.

38. Page A, Ortega A, Alameda JP, Navarro M, Paramio JM, et al. IKK $\alpha$ promotes the progression and metastasis of non-small cell lung cancer independently of its subcellular localization. Comput Struct Biotechnol J 2019;17:251-62.

39. Gonzalez-Suarez E, Jacob AP, Jones J, Miller R, Roudier-Meyer MP, et al. RANK ligand mediates progestin-induced mammary epithelial proliferation and carcinogenesis. Nature 2010;468:103-7.

40. Schramek D, Leibbrandt A, Sigl V, Kenner L, Pospisilik JA, et al. Osteoclast differentiation factor RANKL controls development of progestin-driven mammary cancer. Nature 2010;468:98-102.

41. Tan W, Zhang W, Strasner A, Grivennikov S, Cheng JQ, et al. Tumour-infiltrating regulatory T cells stimulate mammary cancer metastasis through RANKL-RANK signalling. Nature 2011;470:548-53.

42. Wu RC, Qin J, Hashimoto Y, Wong J, Xu J, et al. Regulation of SRC-3 (pCIP/ACTR/AIB-1/RAC-3/TRAM-1) coactivator activity by I kappa B kinase. Mol Cell Biol 2002;22:3549-61.

43. Park KJ, Krishnan V, O’Malley BW, Yamamoto Y, Gaynor RB. Formation of an IKK $\alpha$-dependent transcription complex is required for estrogen receptor-mediated gene activation. Mol Cell 2005;18:71-82.

44. Bennett L, Quinn J, McCall P, Mallon EA, Horgan PG, et al. High IKK $\alpha$ expression is associated with reduced time to recurrence and cancer specific survival in oestrogen receptor (ER)-positive breast cancer. Int J Cancer 2017;140:1633-644.

45. Hossain F, Sorrentino C, Ucar DA, Peng Y, Matossian M, et al. Notch signaling regulates mitochondrial metabolism and NF- $\kappa B$ activity in triple-negative breast cancer cells via IKK $\alpha$-dependent non-canonical pathways. Front Oncol 2018;8:575.

46. Folmer F, Jaspars M, Dicato M, Diederich M. Marine natural products as targeted modulators of the transcription factor NF-kappaB. Biochem Pharmacol 2008;75:603-17.

47. Ríos JL, Recio MC, Escandell JM, Andújar I. Inhibition of transcription factors by plant-derived compounds and their implications in inflammation and cancer. Curr Pharm Des 2009;15:1212-37.

48. Castro AC, Dang LC, Soucy F, Grenier L, Mazdiyasni H, et al. Novel IKK inhibitors: $\beta$-carbolines. Bioorg Med Chem Lett 2003;13:2419-22.

49. Habineza Ndikuyeze G, Gaurnier-Hausser A, Patel R, Baldwin AS, et al. A phase I clinical trial of systemically delivered NEMO binding domain peptide in dogs with spontaneous activated B-cell like diffuse large B-cell lymphoma. PLoS One 2014;9:e95404.

50. Lee DF, Hung MC. Advances in targeting IKK and IKK-related kinases for cancer therapy. Clin Cancer Res 2008;14:5656-62.

51. Shukla S, Kanwal R, Shankar E, Datt M, Chance MR, et al. Apigenin blocks IKK $\alpha$ activation and suppresses prostate cancer progression. Oncotarget 2015;6:31216-32.

52. Leopizzi M, Cocchiola R, Milanetti E, Raimondo D, Politi L, et al. IKK $\alpha$ inibition by a glucosamine derivative enhances Maspin expression in osteosarcoma cell line. Chem Biol Interact 2017;262:19-28.

53. Anthony NG, Baiget J, Berretta G, Boyd M, Breen D, et al. Inhibitory kappa B kinase $\alpha$ (IKK $\alpha$ ) inhibitors that recapitulate their selectivity in cells against isoform-related biomarkers. J Med Chem 2017;60:7043-66. 
54. Lam LT, Davis RE, Pierce J, Hepperle M, Xu Y, et al. Small molecule inhibitors of IkappaB kinase are selectively toxic for subgroups of diffuse large B-cell lymphoma defined by gene expression profiling. Clin Cancer Res 2005;11:28-40.

55. Schön M, Wienrich BG, Kneitz S, Sennefelder H, Amschler K, et al. KINK-1, a novel small-molecule inhibitor of IKK $\beta$, and the susceptibility of melanoma cells to antitumoral treatment. J Natl Cancer Inst 2008;100:862-75.

56. Dai L, Aye Thu C, Liu XY, Xi J, Cheung PC. TAK1, more than just innate immunity. IUBMB Life 2012;64:825-34.

57. Sakurai H, Shigemori N, Hasegawa K, Sugita T. TGF-beta-activated kinase 1 stimulates NF-kappa B activation by an NF-kappa B-inducing kinase-independent mechanism. Biochem Biophys Res Commun 1998;243:545-9.

58. Yamaguchi K, Shirakabe K, Shibuya H, Irie K, Oishi I, et al. Identification of a member of the MAPKKK family as a potential mediator of TGF- $\beta$ signal transduction. Science 1995;270:2008-11. 